\title{
Implantação do Teste Rápido para HIV no CTA - Centro de Testagem e Aconselhamento de São José do Rio Preto-SP
}

Ricardo dos Santos, Rita de Cássia Romero, Silvio Luiz Mano Sanchez

Secretaria Municipal de Rio Preto. CTA - Centro de Testagem e Aconselhamento em DST/AIDS.

Endereço: Rua Ipiranga, 291, Vila Esplanda, CEP 15025520, São José do Rio Preto, SP, Brasil.

E-mail: aids-ctacoas@empro.com.br

O Centro de Testagem e Aconselhamento, serviço de diagnóstico para HIV, Sífilis e Hepatites virais da Secretaria Municipal de Saúde de São José do Rio Preto-SP, implantou a testagem rápida como diagnóstico para o HIV, a partir de dezembro de 2006. Essa é mais uma das estratégias que o Ministério da Saúde, em parceria com os serviços, está disponibilizando para as populações mais vulneráveis, com a proposta de 
ampliar o acesso ao diagnóstico precoce, viabilizando o encaminhamento das pessoas com resultados positivos para o tratamento com mais agilidade. 0 objetivo deste trabalho foi traçar o perfil dos usuários atendidos pelo CTA, desde o período da implantação até dezembro de 2007. Houve um aumento significativo pela procura dos testes: 645 (39\%) por metodologia convencional, 1624 (71\%) por teste rápido, representando um acréscimo percentual de 12,7\% em relação a 2005. 